\title{
Analysis of the MORT method applicability for risk management in supply chains
}

\author{
Ualison Rébula de Oliveira ${ }^{1}$ (1) . Camila Oliveira dos Santos ${ }^{1} \cdot$ Gabriel Elias Lunz Chaves ${ }^{1}$. \\ Vicente Aprigliano Fernandes ${ }^{2}$ (1)
}

Received: 5 August 2021 / Revised: 13 December 2021 / Accepted: 17 December 2021 / Published online: 28 January 2022

(c) The Author(s), under exclusive licence to Springer Science+Business Media, LLC, part of Springer Nature 2021

\begin{abstract}
Although the Management Oversight and Risk Tree (MORT) method is considered a respected analytical procedure to investigate causes and contributing factors of accidents and incidents in different types of businesses, its application in Supply Chain Risk Management was not found in the literature (SCRM). Given this gap, the general objective of this research is to analyze the applicability of the MORT Method in SCRM. Methodologically, the research was supported by an in-depth case study in a cylinder requalification company located in Rio de Janeiro (Brazil). The case study included document analysis, direct observation and structured interviews based on questions previously defined by the MORT Method. As the main theoretical contribution, the research applied, in an innovative way, the MORT Method in SCRM. As the main practical contribution, sequenced, detailed and exemplified steps were developed, so that the MORT Method can be reproduced by other professionals in supply chains. As a limitation, it is observed that the case study only covers the cylinder requalification process, focusing on endogenous risks and failing to address exogenous risks in the supply chain. As a main result, it was possible to identify all the factors that contributed to the damage to cylinder valves; damage that has the potential to have severe consequences for other companies in the supply chain.
\end{abstract}

Keywords Supply chain risk management $\cdot$ SCRM $\cdot$ Supply chain management $\cdot$ Risk analysis $\cdot$ Management oversight and risk tree $\cdot$ MORT method

\section{Introduction}

According to Machado and De Oliveira (2021), a risk management process is based on an analysis of the origins of incidents, where one seeks to understand the forces that can drive a given sequence of events. This analysis can also

Ualison Rébula de Oliveira ualisonrebula@id.uff.br

Camila Oliveira dos Santos camilasantos@id.uff.br

Gabriel Elias Lunz Chaves gabriellunz@id.uff.br

Vicente Aprigliano Fernandes

vicente.aprigliano@pucv.cl

1 Universidade Federal Fluminense (UFF) / MPA-PPGA and MSG-LATEC, 783 Des. Ellis Hermydio Figueira St, Rio de Janeiro 27213-145, Brazil

2 Instituto de Geografia, Pontificia Universidad Católica de Valparaíso, Av. Brasil 2241, Valparaíso 2362807, Chile improve the chances of positive results in terms of performance or avoid future negative consequences of an incident. The variety of management perspectives and measurement systems reflects the complexity of real-life (Ritchie and Brindley 2007).

Intending to avoid incidents, companies are using techniques to prevent and/or minimize failures (De Oliveira et al. 2010, 2021; Santos et al. 2018; Dias et al. 2020). In this sense, Reyes et al. (2010) argues about the importance of the tools for analyzing accidents and incidents in the risk management process, with the purpose of understanding how an event occurred, so that lessons can be learned and, consequently, avoid future recurrences.

It is observed in the literature the existence of numerous tools for Risk Management (ISO 2009; De Oliveira et al. 2018; Dias et al. 2021). Each of them with its purpose (to identify and/or analyze and/or evaluate risks and/or other actions) and the appropriate sector for the risk management application (chemical industry, manufacturing, steel, food, services, among others). As an example, and based 
on recent publications, Rezaee et al. (2020) propose the use of the Failure Mode and Effect Analysis (FMEA) tool to assess Health, Safety and Environment risks in the chemical industry's sector. Kim et al. (2020) used the Fault Tree Analysis (FTA) tool to assess risks associated with microbial contamination in food. Santos and De Oliveira (2019) analyzed thirty-one tools from ISO 31010 for the management of occupational risks in the film and television industry.

FMEA and FTA are some of the most widely used risk management tools found in the literature. However, there are others in which the exact opposite occurs, meaning that there is almost no research material. An example of this occurs with the Management Oversight and Risk Tree (MORT) technique. As evidence of this, on June 2, 2021, only nine articles have been found over the past 50 years in a search on the Web of Science (WoS) database, using the following terms in the title, abstract and keywords sections: "MORT" and "INCIDENT"; or "MORT" and "RISK"; or "MANAGEMENT OVERSIGHT AND RISK TREE".

Perhaps one of the "barriers" regarding the MORT application lies in the complex "fault tree" that this method demands and/or in the difficulties to interpret some aspects of its graph (Ferjencik and Kuracina 2008). However, according to some publications on the MORT method, this does not mean that the tool is not relevant. On the contrary, Kingston et al. (2009) consider it a logical expression for an organization to manage its risks effectively. Jooma et al. (2015) and Jooma et al. (2016) consider MORT a structured method that addresses several causal factors to improve the security management system, including human error management, maintenance, supervision, engineering, and security systems. Santos-Reyes et al. (2010), in turn, claim that the MORT method, unlike other methods, has a focus on knowing "what" ocurred, instead of raising questions on "how" it happened.

Although the MORT Method is not related to a specific type of risk (Kingston et al. 2009) - meaning that this method could be applied in numerous contexts and for different types of risks - it was not observed in the literature its application in supply chains. This gap brings us to the following question: is it possible to use the MORT Method for managing supply chain risks? Based on this question, the general objective of this research is to analyze the applicability of the MORT Method in the management of risks in supply chains and, as a secondary objective, it is expected that this study draws the attention of practitioners and academics regarding the potential of this technique.

Both the problem question and the objective of the research are not only based on the finding that there is a gap in the literature on the application of such a tool in the management of supply chain risks, but also and mainly due to the fact that the MORT Method helps organizations to learn relevant lessons about risks, especially at the managerial level (Mohammadfam et al. 2016), which would certainly have a lot to contribute to the SCRM, since, according to Bloss (2009), only 9\% of the managers who participated in their study had high knowledge of issues related to SCRM.

Methodologically, the objective of the research is achieved through a case study, with the application of the MORT method in a cylinder requalification company located in Rio de Janeiro-Brazil. The company in question is an essential part of the supply chain of its main customers (DuPont, Coca-cola, White Martins, Arkema Química Ltda, among others), ensuring the reuse of cylinders by requalifying them.

After being requalified, the cylinders sent by Coca-cola are returned to the company to be filled with $\mathrm{CO}_{2}$; then, they are sold to fast-food restaurants, where they are used in soda machines. The Rio de Janeiro State Water and Sewer Company (CEDAE) buys chlorine from another company; therefore, the cylinders are sent to a company responsible for filling them with chlorine after requalification cylinders return to CEDAE. White Martins sends cylinders that store different types of gases; after requalification, the cylinders are sold to other companies. Below, as an example, Fig. 1 elucidates part of Coca-Cola's supply chain and highlights the link in the chain in which the case study is applied (marked in red).

The reason for choosing this incident (damage to cylinder valves) as the object of study is because, according to the company, its occurrence may generate risks for other organizations along the entire supply chain, such as process interruptions, explosions and fires.
Fig. 1 Stage of the process where the MORT method is applied

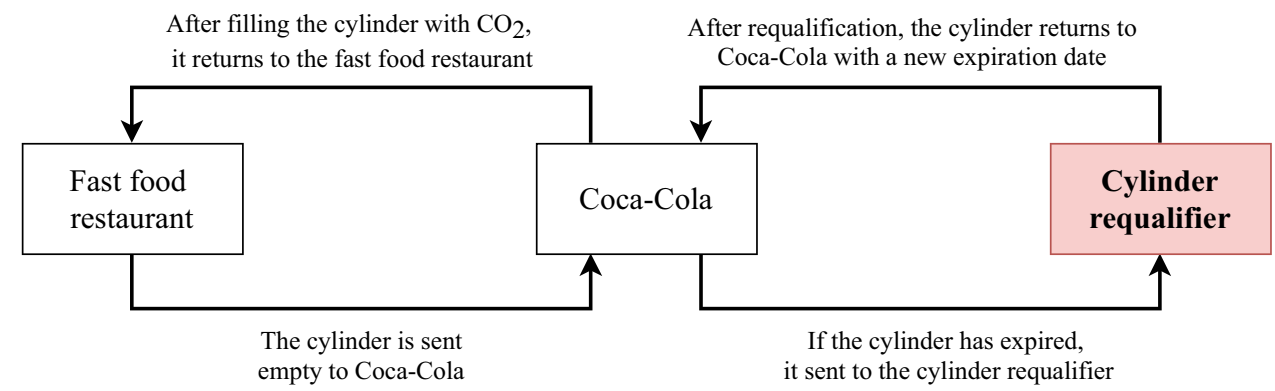


The current study is structured as follows: in the second section, the theoretical framework of this research is presented, which addresses the MORT method; the next section discusses the methods used in the research; the fourth section presents the results obtained in the case study; the fifth section presents the analysis of these results; and finally, in the last section, the main conclusions and suggestions for future research are presented.

\section{Literature review}

Since the focus of this research is related to the analysis of the applicability of the MORT Method for risk management in supply chains (SCRM), the literature review unfolded on two fronts, one for SCRM and the other for MORT method. However, as research on SCRM is increasing (De Oliveira et al. 2018; Dias et al. 2019), with abundant published material and, on the contrary, as publications on the MORT method in journals are scarce, this literature review dedicates a separate subsection on the MORT method. This approach is intended to highlight the MORT method and provide readers with a better understanding of this method.

\subsection{Supply chain risk management (SCRM)}

The use of the expression "Risk Management" in companies emerged around the 1950s, when the Harvard Business Review published an article referring to the topic. The author's proposal was revolutionary: the risks inherent in the organization should be under the responsibility of someone inside the company (Vaughan 1997). However, it is argued that since the $80 \mathrm{~s}$, there have been organizational changes in supply chains for firms to gain cost advantage and market share, and one of these changes is the outsourcing strategy, which from a management point of view could make the supply chain more vulnerable (Tang 2006) since the control over decisions on the chain is decentralized in more than one firm. In the same direction, Manuj and Mentzer (2008) reinforce how this organizational change makes global supply chains more risky than domestic because of the higher complexity in terms of interconnections and extension of the chains. Recognizing the complexity supply chains can have, studies have identified various strategies and elements to be considered to deal with (possible) risks in a supply chain (Ghage et al. 2012; Tang and Musa 2011; Thun and Hoenig 2011). In this direction, Baryannis et al. (2019) and Ahmed et al. (2021), through extensive literature review, looks at the increasing possibility of implementing artificial intelligence methods, such as machine learning, to support the SCRM, considering this complexity a supply chain may have and moreover the amount of data to be processed and analyzed in order to lead to adequate decision-making in the face of the risks and its consequences. Olson and $\mathrm{Wu}$ (2010) emphasize that every organization must respond to the identified risks, and define the objective of risk management as being to minimize or, if possible, eliminate the probability of an unexpected event to happen. If none of these actions are possible, the consequences of this effect must be controlled to the extent that they are acceptable, that is, they do not profoundly affect the company.

Interestingly, Thun and Hoenig (2011), through a comprehensive review of the literature identifies that supply chains are mostly regarded as vulnerable, although there are available SCRM instruments. This is because there are still low levels of application of these instruments in practice. In this direction, there is a high demand for applied studies in this field in order to show practitioners the benefits of SCRM strategies to achieve a more sustainable and resilient chain. However, there has been divergence on the steps and structure one should follow to apply an adequate SCRM, and with this argument, Oliveira et al. (2017), for example, proposes the application of the ISO 31000 standard as a systematic procedure for SCRM. Under a similar argument, de Souza Feitosa et al. (2021) proposes a multi-criteria approach in combination with the fuzzy set theory to support the risk assessment and adequate decision making within a supply chain. This context even opens up the possibility of experimenting with methods not often present in the literature in this field, such as the MORT method, although there is positive experience with SCRM, such as the case of Ericsson, presented by Norrman and Wieland (2020). This company have effectively pursued a proactive and reactive approach on its SCRM, which is aligned with the resilience and robustness concepts within the supply chain context (Munir et al. 2020; Saglam et al. 2020). However, one should recognize that supply chains can have different organization and procedure characteristics, which may difficult a generalization of the SCRM strategies, especially when dealing with firms in developing countries, with fragile economic and political structure (Saglam et al. 2020). An adverse context for SCRM in developing countries also faces social risks related to human rights and labor conditions (Cunha et al. 2019).

Guo (2011) states that, combined with other factors, supply chain management has become an essential element for organizations to obtain a competitive advantage over their competitors today. Organizations are increasingly structured in supply chains to increase value at less cost to the supply chain as a whole (Bouncken 2011). However, supply chain design is a complex process, involving many decisional parameters that require the consideration of numerous sources of uncertainty (Samson and Gloet 2018), mainly due to turbulence in global sales and in the supply markets (Oehmen et al. 2009) and in the today's dynamic nature of demand (Mohib and Delf 2020). According to Guo (2011), 
globalization has created unprecedented opportunities for the development of companies, however, it has increased the risks inherent to the business.

But still, in this globalized context, the terminology "supply chain" may induce practitioners to misunderstand or even overlook risks that threatens a chain. Tummala and Schoenherr (2011) bring a clear view on this problem by drawing attention to the supply chain risk categories and their triggers, such as demand risks with order fulfillment errors, delay risks due to port capacity and congestion, disruption risk related to natural disasters or even terrorism, inventory risks in the face of product obsolescence, and not less important, there are manufacturing risks and physical risks of a plant, which may be seen as internal part of the chain. This could relate to internalized and externalized transactions that a company may have, being all part of a supply chain (Wang-Mlynek and Foerstl 2020), from internal administration and budgeting to manufacturing stages, inventory management and transportation, until the final customer, therefore considering stages of a supply chain within and between companies. This approach is dealt with by Blome and Schoenherr (2011) when they relate enterprise risk management to SCRM in the face of financial/economic crisis through an eight-case studies analysis. They observe that there is a difference between the impact of such crisis in a service and a manufacturing firm. While service firms have more flexibility and lower vulnerability because of the variety of suppliers it may have, a manufacturing firms presents higher risks in the supply and demand side of the chain. However, in general, both types of firms have difficulty on dealing holistically with risks (Blome and Schoenherr 2011), in consequence of a frail and centralized supply chain management strategy.

For Tang (2006), the introduction of risk management in the supply chain helps the organization to avoid these risks, in addition to minimizing them if they occur. Thus, Olson and $\mathrm{Wu}$ (2010) state that supply chains are critical for the contemporary market and risk management in these chains are crucial for organizations, mainly because disruptions and interruptions in the supply chain can generate high monetary value losses and affect the image of organizations (De Oliveira et al. 2017).

In reviewing the study and application of risk management, Khan and Burnes (2007) realized that, within an organization, the risk management process is associated with ways to avoid losses. According to Viswanadham and Gaonkar (2008), there are two ways to manage risks in a supply chain: preventive and interceptive. Preventive is the way to assess risks before they occur; its objective is to reduce the possibility of a deviation or interruption in the chain. In the interceptive form, it is already considered that the chain has been affected, and its function is to minimize the effects and losses with interventions as much as possible. Regardless of the form being preventive or intercepting, numerous researchers (Jüttner et al. 2003; Ritchie and Brindley 2007; Manuj and Mentzer 2008; Tummala and Schoenherr 2011; Kern et al. 2012; De Oliveira et al. 2017; Dias et al. 2021; among others) studied the potential models for SCRM, so that these models could be used to increase resilience and minimize significant interruptions in the supply chain.

With a more specific and exploratory study, Blos et al. (2009) identify risks in the supply chain of automotive and electronic industries in Brazil. It is relevant to stress that this study highlighted risks related to financial, strategic, hazard and operations origins. Specifically, there are internal and external risks to these sectors, from property damage, operator error to dealer and supplier relations, beyond others presented by Blos et al. (2009). Under the identified risk, Blos et al. (2009) see as fundamental the training of personal in terms of supply chain planning and even pointing out the need to create specific job positions in the studied sectors focused on the management of supply chain risks. In this direction, through an empirical study, Creazza et al. (2021) emphasize the importance of managers' perception and how this may influence the decisionmaking within a chain. However, due to employee turnover, there may be knowledge loss by the company affecting the flow of the supply chain (Daghfous et al. 2021), which may be even more concerning when this turnover is related to managing positions.

From a broader perspective, Baz and Ruel (2021) evaluate the capability of SCRM practices to mitigate the impacts in the context of the COVID-19 outbreak in terms of resilience and robustness, looking into survey data of 470 French firms. This study shows the importance of differentiating the concepts of robustness and resilience when applied to a supply chain context. While robustness deals with the ability to keep up with the planned performance in the face of disruption, the resilience approach relates to recovering performance after the disruption impact (Baz and Ruel 2021). Also, it should be noted that this study evaluated the practices based on the analysis of four traditional SCRM processes: risk identification; risks assessment; risk mitigation; and risk control. Similarly, Ahmed and Huma (2021) emphasize the resilience and robustness approach, however, with the objective of proposing a conceptual framework to improve the effectiveness of the leagile strategy for SCRM, which is a combination of lean and agile strategy.

There are several approaches of SCRM applied to a variety of sectors of the economy in pursue of bettering the risk identification and decision-making process to reduce the vulnerability of a supply chain. However, it should be observed that most studies focus on the response of private companies, while there is also a need to look at the potential of implementing SCRM techniques in organization with less 
financial and human resources, such as relief organizations that acts on humanitarian purpose (Azmat et al. 2019).

Specifically on techniques for risk management applied in supply chains, also referred to in the literature as "tools" (an example of this is in the ISO 31010 standard), it is observed the application and use of FMEA (Chen and $\mathrm{Wu}$ 2013), Decision Tree (Ruiz-Torres et al. 2013), Bayesian Network (Ojha et al. 2018), Delphi Method (Kwak et al. 2018), Markov Analysis (Hosseini et al. 2020), Multi Criteria Decision Analysis (Abdel-Basset and Mohamed 2020), Risk indices (Dias et al. 2021), Monte Carlo Simulation (Silva et al. 2021), among many other techniques. However, no application of the MORT Method was found in Supply Chain studies. For this reason, the next subsection will cover this method in more detail, mainly because, according Wang et al. (2017), there is an urgent demand for practical tools that support SCRM.

\subsection{Management oversight and risk tree (MORT)}

The MORT method is an old and respected technique in identifying causes of incidents (Ferjencik and Kuracina 2008) and it can be considered as a checklist that is structured in the form of a complex model of " fault tree ". This model aims to ensure that all aspects of an organization are analyzed when evaluating the possible causes of an incident or accident (Santos-Reyes et al. 2009, 2010). An accident is defined as an unplanned event that results in personal injury or property damage and an incident is defined as an unplanned event that does not result in personal injury but may result in property damage or is worthy of recording (Gopalaswami and Han 2020).

The MORT method consists of a detailed method for the categorization of organizational and managerial deficiencies that generate incidents (Gerbec 2013). Moreover, SantosReyes and Olmos-Pena (2017) note that the MORT method aims to analyze several organizational failures that led to an accident. It is an analytical procedure to investigate the causes and factors that contribute to accidents and incidents. In addition, it is a logical expression of necessary procedures for organizations to manage their risks effectively. Unlike other tools, these procedures emphasize on "what" took place, rather than "how" it occurred (Kingston et al. 2009).

The NRI Mort User's manual (referred in this manuscript as NRI-1), developed by Kingston et al. (2009), proposes the application of the tool in three stages: defining the events to be analyzed; define each event in relation to undesirable energy transfers; and evaluate the hypothesis that these undesirable energy transfers were the result of the way the risks were managed in the activity that the accident arose. In the first stage, a barrier analysis and energy tracking is carried out in order to identify a set of events, including the specific incident or accident; moreover, it seeks to define each event clearly. Then, in step two, the analyst looks at how the energy impacts people or assets, looking at how the damage or danger affected an organization or people. Finally, in step three, the analyst seeks to understand how the activity was managed, with a focus on the specific location where the accident took place, seeking to observe how the management is carried out concerning the resources, processes and equipment that are relevant to the accident (Kingston et al. 2009).

The MORT method can be summarized as a process of responding to a series of questions in order to understand "what occurred" and "why it occurred" (Reyes et al. 2010). The tree structure of the MORT method comes from a tree analysis of event failures. It is generic and can be used for any type of risk. Its process consists of inputs, outputs and logic gates, in which the inputs and outputs are usually the result of events and the logic gates are elements that are generally used in a theoretical context (Kingston et al. 2009).

According to Kingston et al. (2009), after identifying the "loss-event", to proceed to the first level of the tree, it is essential to answer the question "What types of risk would produce losses?". There are two alternative answers: risks that have not been managed, known as "carelessness and omissions"; or "assumed risks". For a better interpretation of the analysis, the determined sequence to be explored starts from top to bottom, from left to right.

The MORT method can be divided into two parts, "specific control" and "management system"; these constitute the top of the main branch, being identified, respectively, with the capital letters "S" and "M" (see Fig. 2).

The second part is related to the tree level; "A" indicates one level below, "B" two levels below and so on until the letter "D" (Fig. 2). Within the levels, branches are identified with the lower-case letters "a", "b", "c" and so on. It is observed that the organization of the letters refers to a hierarchical sequence (Kingston et al. 2009).

According to Kingston et al. (2009), the main objectives of the analysis based on the MORT method is to understand how the loss occurred and to explain it in terms of risk management. Thus, this method is adequate for the analysis of events that may represent a high risk. For its application, it is necessary to fulfill some basic requirements. It is advisable that two people who have a technical understanding of the accident can carry out a sequential description of the occurred events in order to begin the analysis. In addition, it is essential to identify the occurred facts with the colors red, green or blue. If the data are not enough to evaluate an element, it should be highlighted in blue, as they need more information; the green color highlights data that can prove the event, but does not reveal the source of the problems; the red color highlights the facts that need to be justified as a proof of such an event, as they are the main points to be analyzed (reveals the problem).

First, it is essential to identify the "T", the top event. For this, two questions are answered: "What happened?"; 
Fig. 2 Main tree branches of the MORT method. Source: Adapted from Kingston et al. (2009)

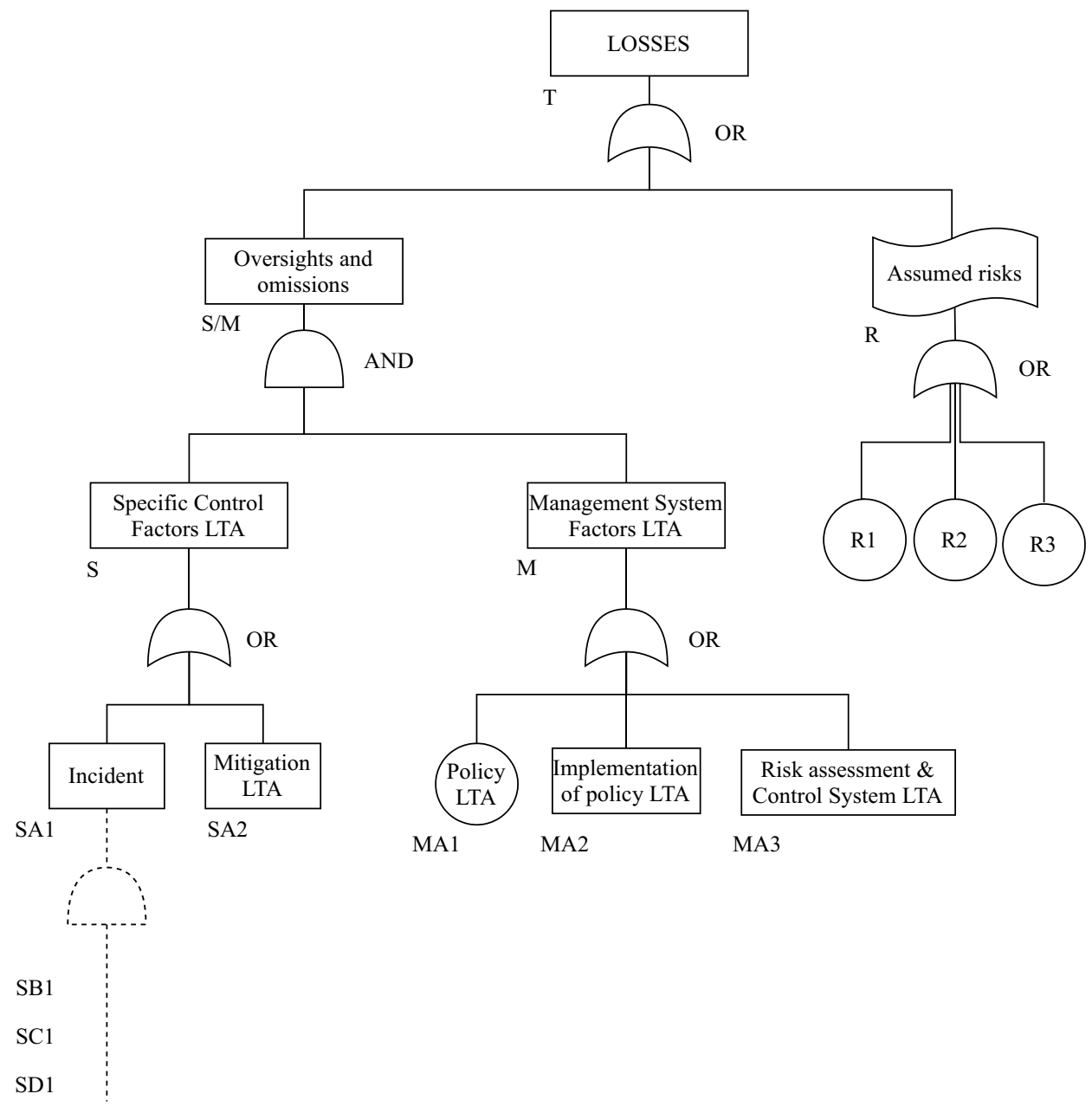

and "What was the sequence of events, including the initial event that transformed the work/process from properly controlled to uncontrolled?". Having answered these questions, the analysis begins, determining why the loss occurred and what could be the future problems resulting from the identified event (Kingston et al. 2009). In Fig. 2, it is possible to observe that the tree considers two possible causes. The first occurs due to "carelessness and omissions", being subdivided and indicated by the letters: "S" (control factors); and "M" (management system factors). In the second, the assumed risk is considered acceptable in the process, known by the letter "R". These and the next acronyms are better described in Table 1.

Finally, the tree structure of the MORT method is composed of several elements, which address the most varied themes about the accident/incident; each has pre-established questions contained in the NRI-1 manual. The decision to use an element or not was made considering its relevance in the context of the situation. When an element was deemed relevant, it was signaled in the MORT method tree in red or green or blue. The following flowchart, in Fig. 3, elucidates this approach.

\section{Materials and methods}

The method used in the research had two main stages: bibliographic review; and case study. In the first stage, we sought to carry out a literature review on the MORT method. In the second stage, efforts were made to apply the MORT method, and, for that, a case study was carried out in a cylinder requalification company. It is important to highlight that the cylinder requalification company for the applied case study is certified by National Institute of Metrology, Quality and Technology (INMETRO), which is an organization in Brazil that carries out all the necessary procedures to condemn or approve the reuse of cylinders. The company chosen for the case study in question has 20 years of experience, provides services in the areas of manufacturing inspection, certification and requalification of cylinders for packaging and transport of gases at high and low pressure. It contains fourteen employees; of these, three work in the administrative part and the other eleven in the operational part. Its main customers are DuPont Brasil, Coca-Cola and White Martins.

Initially, document analysis was adopted as a data collection instrument, with the aim of learning about all the 
Table 1 Steps of the MORT method graph and its functions

\begin{tabular}{|c|c|c|}
\hline Acronym & Terminology & Function \\
\hline $\mathrm{T}$ & Losses & $\begin{array}{l}\text { In this phase, the extent of damage and loss is described, answering the } \\
\text { following questions: } \\
\text { - "What happened?" } \\
\text { - "What was the sequence of events?" }\end{array}$ \\
\hline $\mathrm{S} / \mathrm{M}$ & Carelessness and Omissions & $\begin{array}{l}\text { It considers whether the accident occurred due to problems in the } \\
\text { planning, design or control of the work/process }\end{array}$ \\
\hline S & Control factors LTA & $\begin{array}{l}\text { It identifies the seriousness of the problems through controls and } \\
\text { barriers of harmful energies, people, goods and emergency actions }\end{array}$ \\
\hline SA1 & Accidents/Incidents & $\begin{array}{l}\text { The decision on the transfer of energy is indicated in this part. The } \\
\text { analysis recognizes factors in the management system and the } \\
\text { judgment of accepting the risks or not }\end{array}$ \\
\hline
\end{tabular}

SB1 Potentially harmful energy flow or environmental condition

In this branch, the objective is to obtain a broad view of environmental control and harmful energy issues

SB2 Vulnerable people or objects

This branch considers who or what was exposed to the harmful energy flow. A loss occurs when someone is injured, or something of value is damaged. However, in the MORT method, this loss is also considered when the energy is out of control

SB3 Control and barrier LTA

At this point, it is assessed whether protective barriers and work and process controls were in place to prevent vulnerable people and objects from being exposed to the flow of harmful energy and/or environmental conditions

SC1 Control of the work process LTA

At this point, it is considered the appropriation of the control of the system, the work activity or process under analysis, which must be able to clearly expose the issue in question. Six points are considered: technical information system; operational readiness; inspection; maintenance; supervision and staff; and supervisory support

SD1 Technical information system LTA

It is the branch that supports the relevant work processes, in three ways: producing information about technologies and materials implemented; systems that indicate workflow competency; and actions resulting from monitoring

SD2 Operational readiness LTA

It is considered as if the appropriate efforts are ready to ensure that the work/process is put in place. Otherwise, with an inadequate work/ process, one must consider: plant/hardware; control/management procedure; and staff

SD3 Inspection LTA

SD4 Maintenance LTA

SD5 Supervision and performance team LTA

SD6 Supervisory support LTA

Checks the quality of equipment, processes, operations, etc

It is the branch that contributes to the maintenance of equipment, processes, etc. It can be done internally or externally

The purpose of this branch is to observe the role of control and personal performance in the management of work and process, ensuring that the work is performed without difficulty, detecting and correcting risks

It is in this branch that the management of the higher level is judged, collaborating with the organization correctly

SC2 Barriers LTA

SB4 Events and energy flows that led to the accident/incident

SA2 Stabilization and restoration LTA

Identifies the barriers that should be protecting the target and were not

It is necessary to decide between the various interactions of energy and targets to be considered, each of which must be investigated separately. These interactions are verified through the analysis of barriers

It is intended to measure the events that occurred after a harmful event, making every effort to reduce the impacts of the occurrence of the event

M Management system factors LTA

At this point, projects, planning or policy creation processes are deemed necessary, as it can contribute to the event

MA1 Policy LTA

MA2 Policy implementation LTA

It refers to a specific policy theme, already identified in $\mathrm{M}$, in which it highlights the importance and research on the issue

In this field, the problem at hand is the result of a policy adopted. It is relevant to know the way it was designed and implemented, as well as its purpose 
Table 1 (continued)

\begin{tabular}{|c|c|c|}
\hline Acronym & Terminology & Function \\
\hline MA3 & Risk management system LTA & This "branch" recognizes the adaptation of the risk management system \\
\hline MB1 & Risk management policy LTA & It considers whether the risk management was properly performed \\
\hline MB2 & Implementation of the risk management policy LTA & $\begin{array}{l}\text { In this phase, it seeks to find out if the specific problem is the result of } \\
\text { the risk management policy adopted }\end{array}$ \\
\hline MB3 & Risk analysis process LTA & $\begin{array}{l}\text { At this stage, risk research, its concept, the composition of processes } \\
\text { and specific work activities are studied }\end{array}$ \\
\hline MB4 & Risk management guarantee program LTA & It aims to certify risk management in relation to processes \\
\hline MB5 & Review of the risk management system LTA & $\begin{array}{l}\text { At this stage it is essential to answer four questions: } \\
\text { - "Did the organization ensure that a review of the risk management } \\
\text { system was carried out periodically?"; } \\
\text { - "Was the review adequate to ensure the application and effectiveness } \\
\text { of the risk management system?"; } \\
\text { - "Were the reviews properly documented and implemented?"; } \\
\text { - "Was there an adequate external review?" }\end{array}$ \\
\hline $\mathrm{R}$ & Assumed Risk & $\begin{array}{l}\text { Finally, in order to identify the risk assumed, answers to the following } \\
\text { questions are required: } \\
\text { - "What were the assumed risks?"; } \\
\text { - "Were they specific events?"; } \\
\text { - "Were they analyzed and, when possible, quantified?"; } \\
\text { - "Was there a specific decision to take each risk?"; } \\
\text { - "Was the decision made by a person who had the competence and } \\
\text { authority to take the risk?" }\end{array}$ \\
\hline
\end{tabular}

Source: Adapted from Kingston et al. (2009)

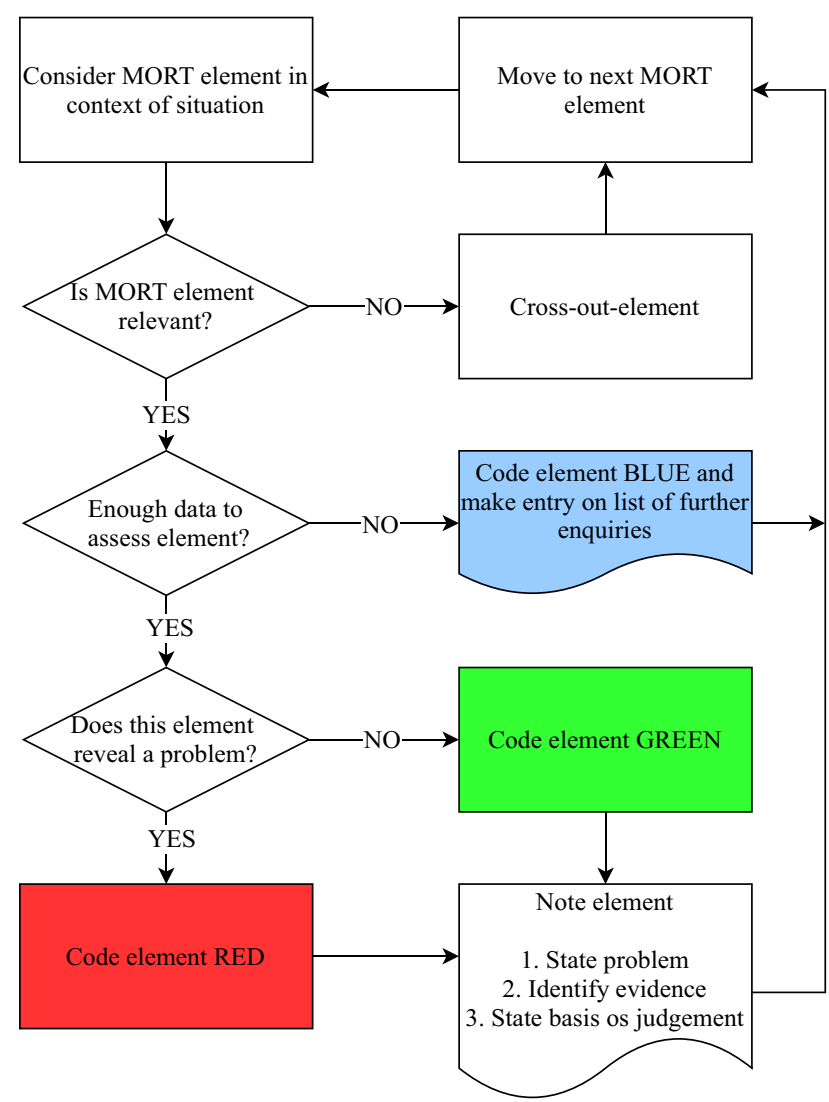

Fig. 3 Considerations for solving the MORT method graph. Source: Adapted from Kingston et al. (2009) company's processes. In this phase, documents containing flowcharts, explanations of the processes and activities, number of employees per job and tools/equipment used were analyzed. Afterward, direct observation was used to verify, understand and analyze the functioning of these processes, especially those that are linked to the study problem. The observation was made during one month, in the morning, twice a week. Both document analysis and direct observation were essential for understanding and mapping the target process of this research.

Finally, interviews were carried out with two employees from the operational area, one being a coordinator and the other an operations manager; both with 20 years of professional experience in the target company of the empirical research. Such interviews were conducted based on questions from the NRI-1 Manual (see Table 1).

It was chosen to follow the sequence of steps described above (literature review, document analysis, direct observation and interviews) to enable an in-depth analysis of the applicability of the MORT Method for risk management in a process that, in this case of failures, it could cause a rupture between Tier 2 (cylinder reclassifier), Tier 1 (e.g., Coca-Cola) and customer (e.g., Fast Food Restaurant). This mix of methodological procedures is classified by Yin (2017) as a case study, which often uses more than one technique to collect data that converge to a common objective. 


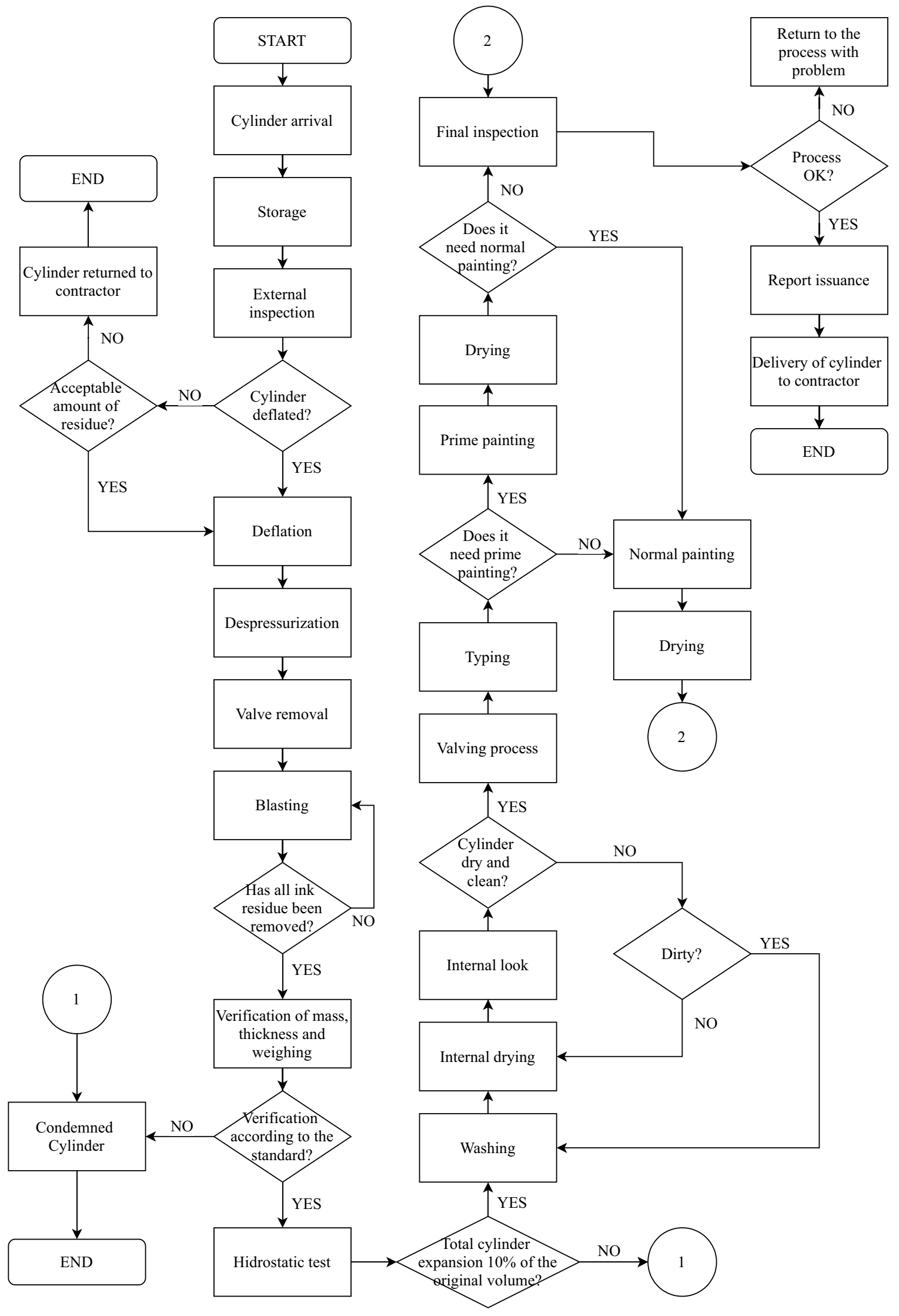

Fig. 4 Mapping the cylinder requalification process 
Table 2 Description of the cylinder requalification process

\begin{tabular}{|c|c|c|}
\hline Stages & Process & Description \\
\hline $1^{\mathrm{a}}$ & Cylinder arrival & Arrival of the cylinder, together with the service order \\
\hline $2^{\mathrm{a}}$ & Storage & The cylinder is stored section outside the company \\
\hline $3^{\mathrm{a}}$ & External inspection & The cylinder manufacturing data, corrosion, cracks are verified \\
\hline $4^{\mathrm{a}}$ & Deflation & $\begin{array}{l}\text { The cylinder is degased (gas removal process) and for this purpose products used vary according to the type of } \\
\text { product stored in each cylinder. The cylinder must arrive at the company empty with caustic soda or lime so } \\
\text { that it does not have any type of residue inside, but in most cases this does not occur, and the contractor must } \\
\text { perform this process. In addition, at this stage, the removal of chlorine odor from the inside of the cylinder is } \\
\text { also guaranteed. In cases of excess chlorine inside the cylinder, it is returned to the contractor }\end{array}$ \\
\hline $5^{\mathrm{a}}$ & Depressurization & Process in which pressure is removed from the cylinder \\
\hline $6^{\mathrm{a}}$ & Valve removal & Process in which the valve is removed using a wrench \\
\hline $7^{\mathrm{a}}$ & Blasting & $\begin{array}{l}\text { The cylinder is inserted in an isolated cabin and, using steel shot, all its paint is removed. The process is only } \\
\text { completed after removing all the ink from the cylinder. After completion, the employee, through a sieve, } \\
\text { separates the paint and the waste from the steel shot in order to reuse the steel shot }\end{array}$ \\
\hline $8^{\mathrm{a}}$ & $\begin{array}{l}\text { Verification of mass, } \\
\text { thickness and } \\
\text { weighing }\end{array}$ & $\begin{array}{l}\text { Verification of Mass, Thickness and Weighing-an ultrasound is used in this process. Each cylinder must meet } \\
\text { defined standards for mass, thickness and weighing }\end{array}$ \\
\hline $9^{a}$ & Hydrostatic test & $\begin{array}{l}\text { The cylinder is filled with water, then a pressure is applied to the cylinder to measure its expansion, which } \\
\text { should not exceed } 10 \% \text { of the total; if the expansion is greater than recommended, the cylinder is condemned. } \\
\text { The water that is removed from the cylinder is weighed on a scale, as the weighing indicates the volume that } \\
\text { the cylinder has expanded, or is measured with a burette-a cylindrical laboratory instrument that has a } \\
\text { rigorous graduated scale }\end{array}$ \\
\hline $10^{\mathrm{a}}$ & Washing & $\begin{array}{l}\text { Then, the cylinder is washed with water, at a temperature of } 90^{\circ} \mathrm{C} \text { to remove residues and clean inside; the } \\
\text { water vapor itself assists in its internal drying }\end{array}$ \\
\hline $11^{\mathrm{a}}$ & Internal drying & $\begin{array}{l}\text { Drying must be carried out by circulating completely dry air inside the cylinder, in order to ensure that at the } \\
\text { end of the operation there is no moisture inside the cylinder. This procedure is performed with high pressure } \\
\text { blowing or aspiration }\end{array}$ \\
\hline $12^{\mathrm{a}}$ & Internal look & $\begin{array}{l}\text { It is verified with the naked eye, with the aid of a twelve-volt lamp, if there are any substances inside the } \\
\text { cylinder (water, dirt or other product) }\end{array}$ \\
\hline $13^{\mathrm{a}}$ & Valving process & Process performed manually to install the valve on the cylinder; this valve may be new or not \\
\hline $14^{\mathrm{a}}$ & Typing & $\begin{array}{l}\text { The month and the year in which it was restocked are identified on the cylinder; this service is performed } \\
\text { manually }\end{array}$ \\
\hline $15^{\mathrm{a}}$ & Painting & $\begin{array}{l}\text { Painting is done manually, using compressed air and paint in a booth. This painting can be prime and normal, } \\
\text { prime, or just normal }\end{array}$ \\
\hline $16^{\mathrm{a}}$ & Drying & $\begin{array}{l}\text { Drying is carried out naturally, making its time vary according to the ambient temperature and the type of paint } \\
\text { used. The cylinder is hung on an overhead conveyor or placed on the floor until it is completely dry, in } \\
\text { addition, the handling of some types of paint can only be done after twenty-four hours. To find out if the } \\
\text { thickness of the paint is adequate, an equipment is used for the exact measurement of the thickness }\end{array}$ \\
\hline $17^{\mathrm{a}}$ & Final inspection & Quality control of the service provided \\
\hline $18^{\mathrm{a}}$ & Report issuance & It consists of a grouping of all the data related to the tested cylinder \\
\hline $19^{\mathrm{a}}$ & Delivery & $\begin{array}{l}\text { The means of transport for the delivery of the cylinder varies according to the initial negotiation with the } \\
\text { customer }\end{array}$ \\
\hline
\end{tabular}

Source: Own elaboration

\section{Research results}

\subsection{Process mapping}

As proposed to Kingston et al. (2009), to start the first stage of the analysis of the MORT method, it was necessary to sequence the activities where the incident occurred. For this, first, a flowchart was used in order to understand the operation of the cylinder requalification service and, thus, to identify in which of the processes the incident occurred. The "Valve Removal" and "Valving process" processes were identified as the locations responsible for the incident, so a second flowchart was performed in order to learn about the activities carried out in these two processes. The flowchart in Fig. 4 represents the cylinder requalification service processes; then, Table 2 explains each process in detail.

The flowcharts in Fig. 5 represent the activities of the "Valve Removal" and "Valving process". 


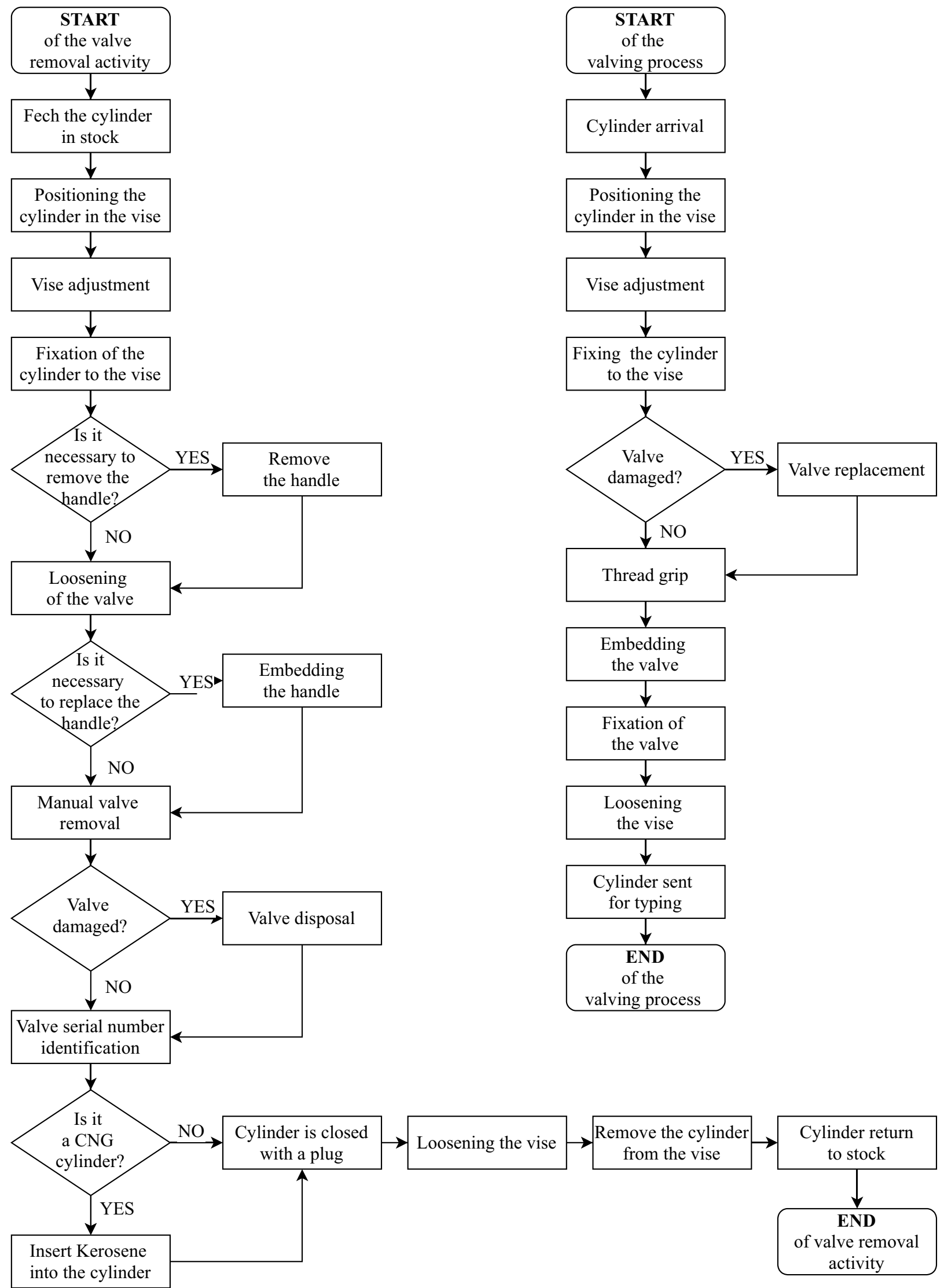

Fig. 5 "Valve removal" (left) and "Valving process" (right) activities 
Table 3 Valve Removal Process

\begin{tabular}{|c|c|c|c|}
\hline Activity & Energy flow & Target & Controls and barriers \\
\hline Fetch cylinder from stock & Cylinder & Staff (lesion) & Personal Protective Equipment (PPE) \\
\hline Fetch cylinder from stock & Staff & Valve (damage) & Absence of barriers and controls \\
\hline Positioning the cylinder in the vise & $\begin{array}{l}\text { Vise for cylinder valving process and } \\
\text { extender }\end{array}$ & Staff (lesion) & PPE \\
\hline Positioning the cylinder in the vise & Vise for the valving process the cylinder & Valve (damage) & Maintenance and Training \\
\hline Removal of the handle & Incorrect handling of the screwdriver & Handle/valve(damage) & Absence of barriers and controls \\
\hline Loosening the valve & Incorrect handling of the wrench & Staff (lesion) & PPE and training \\
\hline Loosening the valve & Incorrect handling of the wrench & Valve (damage) & Absence of barriers and controls \\
\hline Handle installation & Incorrect handling of the screwdriver & Handle/valve(damage) & Absence of barriers and controls \\
\hline Loosening of the vise & $\begin{array}{l}\text { Vise for cylinder valving process and } \\
\text { extender }\end{array}$ & Staff (lesion) & PPE and training \\
\hline Cylinder return to stock & Cylinder & Staff (lesion) & PPE \\
\hline Cylinder return to stock & Staff & Valve (damage) & Absence of barriers and controls \\
\hline
\end{tabular}

Source: Own elaboration

\subsection{Analysis of the MORT method}

As explained in the literature review section, the method is divided into three stages; the results of each of them are presented in the following subsections.

\subsubsection{First stage: energy tracking framework and barrier analysis}

The energy tracking and barrier analysis framework, or, simply, barrier analysis framework was used to sequentially identify the energy flows, targets, barriers and controls of existing activities in the "Valve removal" and "Valving process" decision tree. Following the guidance described in NRI-1 manual, only one event of the barrier analysis framework was chosen. The seventh energy flow ("incorrect handling of the wrench"), which targets the valve and has no barriers and control, was chosen to continue the analysis, as it is in this event that the incident occurs (damage to the valve). Tables 3 and 4 represent, respectively, the barrier analysis of the "Valve Removal" and "Valving process" procedures.
Some energy flows are repeated in the tables, meaning that, it has equal targets and barrier. To differentiate them and facilitate the reader's understanding, the "Activity" column was created in Tables 3 and 4 as an addition to the barrier analysis table presented in the NRI-1 manual.

\subsubsection{Second stage: energy transfer framework}

In this step, the focus is to understand how the energy transfers happened, that is, how the energy flows affected the targets. As in Tables 3 and 4, the column "Activity" was created in Tables 5 and 6 to differentiate the energy flows that are repeated and, consequently, facilitate the reader's understanding.

\subsubsection{Third stage: graph of the MORT method}

Finally, the contributing factors for the incident in question were identified using the MORT method graph. The elements were signaled with the colors: i) red, when the element represented a problem or was considered insufficient; ii) green, when the element was considered adequate

Table 4 Valving process

\begin{tabular}{llll}
\hline Activity & Energy flow & Target & Controls and barriers \\
\hline Positioning the cylinder in the vise & Vise for cylinder valving process and extender & Staff (lesion) & PPE \\
Positioning the cylinder in the vise & Vise for cylinder valving process & Valve (damage) & Maintenance and Training \\
Thread grip & Staff & Valve (damage) & Training \\
Fixation of the valve & Incorrect handling of the wrench & Valve (damage) & Absence of barriers and controls \\
Loosening of the vise & Vise for cylinder valving process and extender & Staff (lesion) & PPE and training \\
Cylinder sent for typing & Cylinder & Staff (lesion) & PPE and training \\
\hline
\end{tabular}

Source: Own elaboration 
Table 5 Valve Removal Process

\begin{tabular}{|c|c|c|c|}
\hline Activity & Energy flow & Target & Energy transfer \\
\hline Fetch cylinder from the stock & Cylinder & Staff (lesion) & $\begin{array}{l}\text { When rolling the cylinder around the } \\
\text { yard without using any machinery to } \\
\text { help with transportation, the employee } \\
\text { could be injured if he was not using } \\
\text { PPE. The barrier in this case is the use } \\
\text { of PPE }\end{array}$ \\
\hline
\end{tabular}

Fetch cylinder from the stock Staff Valve (damage)

Positioning the cylinder in the vise Vise for cylinder valving process and extender

Positioning the cylinder in the vise Vise for cylinder valving process

Handle removal

Incorrect handling of the screwdriver

Loosening the valve

Incorrect handling of the wrench

Loosening the valve

Incorrect handling of the wrench

Embedding the handle

Incorrect handling of the screwdriver

Loosening the vise
Vise for cylinder valving process and extender
Staff (lesion)

Handle/valve (damage)

When rolling the cylinder through the yard without using any machinery to help with transportation, the employee could damage the valve by hitting any object that was on the floor. The barrier and/or control in this case does not exist

Staff (lesion)

The employee positioned the cylinder incorrectly and this ended up compromising the "Loosening of the valve" process, as the poorly positioned cylinder generated a bump on the tool (extender) that the employee used. The use of PPE in this case was essential so that the employee was not injured

Valve (damage)

The cylinder positioned incorrectly caused the machine to not to fixate it correctly, which created a risk of the wrench damaging the valve. The control in this case is the training given to employees to position the cylinder in the vise

Handle/valve (damage) The screwdriver being used as a tool to remove the handle generated the possibility of damage to the handle. The barrier and/or control in this case does not exist

The improper fit of the wrench, combined with the employee's excessive force on the valve, generated the possibility of the tool bumping, which could injure the employee. The barrier in this case is the use of PPE and the control is training

Valve (damage)

The improper fitting of the wrench, combined with the employee's excessive force on the valve, generated a jolt and, consequently, the tool disengaged on the valve, damaging it. In addition, the force expended incorrectly in excess corrodes the thread. The barrier and / or control in this case does not exist

The screwdriver being used as a tool for replacing the handle generated the possibility of damaging it. The barrier and/or control in this case does not exist

The force expended to loosen the vise generated a bump on the tool, which could injure the employee if he was not using PPE 
Table 5 (continued)

\begin{tabular}{|c|c|c|c|}
\hline Activity & Energy flow & Target & Energy transfer \\
\hline Return cylinder to the stock & Cylinder & Staff (lesion) & $\begin{array}{l}\text { When rolling the cylinder around the } \\
\text { yard without using any machinery to } \\
\text { help with transportation, the employee } \\
\text { could be injured if he was not using } \\
\text { PPE. The barrier in this case is the use } \\
\text { of PPE }\end{array}$ \\
\hline Return cylinder to the stock & Staff & Valve (damage) & $\begin{array}{l}\text { When rolling the cylinder through the } \\
\text { yard without using any machinery to } \\
\text { help with transportation, the employee } \\
\text { could damage the valve by hitting } \\
\text { any object that was on the floor. The } \\
\text { barrier and/or control in this case does } \\
\text { not exist }\end{array}$ \\
\hline
\end{tabular}

Source: Own elaboration

Table 6 Valving process

\begin{tabular}{|c|c|c|c|}
\hline Activity & Energy flow & Target & Energy transfer \\
\hline Positioning the cylinder in the vise & $\begin{array}{l}\text { Vise for cylinder valving process and } \\
\text { extender }\end{array}$ & Staff (lesion) & $\begin{array}{l}\text { The employee positioned the cylinder } \\
\text { incorrectly, which ended up } \\
\text { compromising the "Loosening of the } \\
\text { valve" process, as the poorly positioned } \\
\text { cylinder generated a bump on the tool } \\
\text { (extender) that the employee used. The } \\
\text { use of PPE in this case was essential so } \\
\text { that the employee was not injured }\end{array}$ \\
\hline
\end{tabular}

Positioning the cylinder in the vise Vise for cylinder valving process

Thread grip

Fixation of the valve

Loosening the vise

Cylinder sent for typing
Incorrect handling of the wrench

Cylinder

Staff

Vise for cylinder valving process and extender

Staff (lesion)

Staff (lesion)
Valve (damage) The cylinder positioned incorrectly caused the machine not to fixate it correctly, which created a risk of the wrench damaging the valve. The barrier and/or control in this case does not exist

Valve (damage) The misplacement of the sealing tape (Teflon) on the cylinder thread generated the possibility of future leakage and/or damage to the valve caused by the lack of thread adhesion. In this case, the training given by the company is the form of control

Valve (damage) The improper fitting of the wrench, combined with the employee's excessive force on the valve, generated a jolt and, consequently, the tool disengaged on the valve, damaging it. In addition, the force expended incorrectly in excess corrodes the thread. The barrier and/or control in this case does not exist

The force expended to loosen the vise generated a bump on the tool (extender), which could injure the employee if he was not using PPE

When rolling the cylinder through the yard without using any machinery to help with transportation, the employee could damage the valve by hitting any object that was on the floor. The barrier and/or control in this case does not exist 


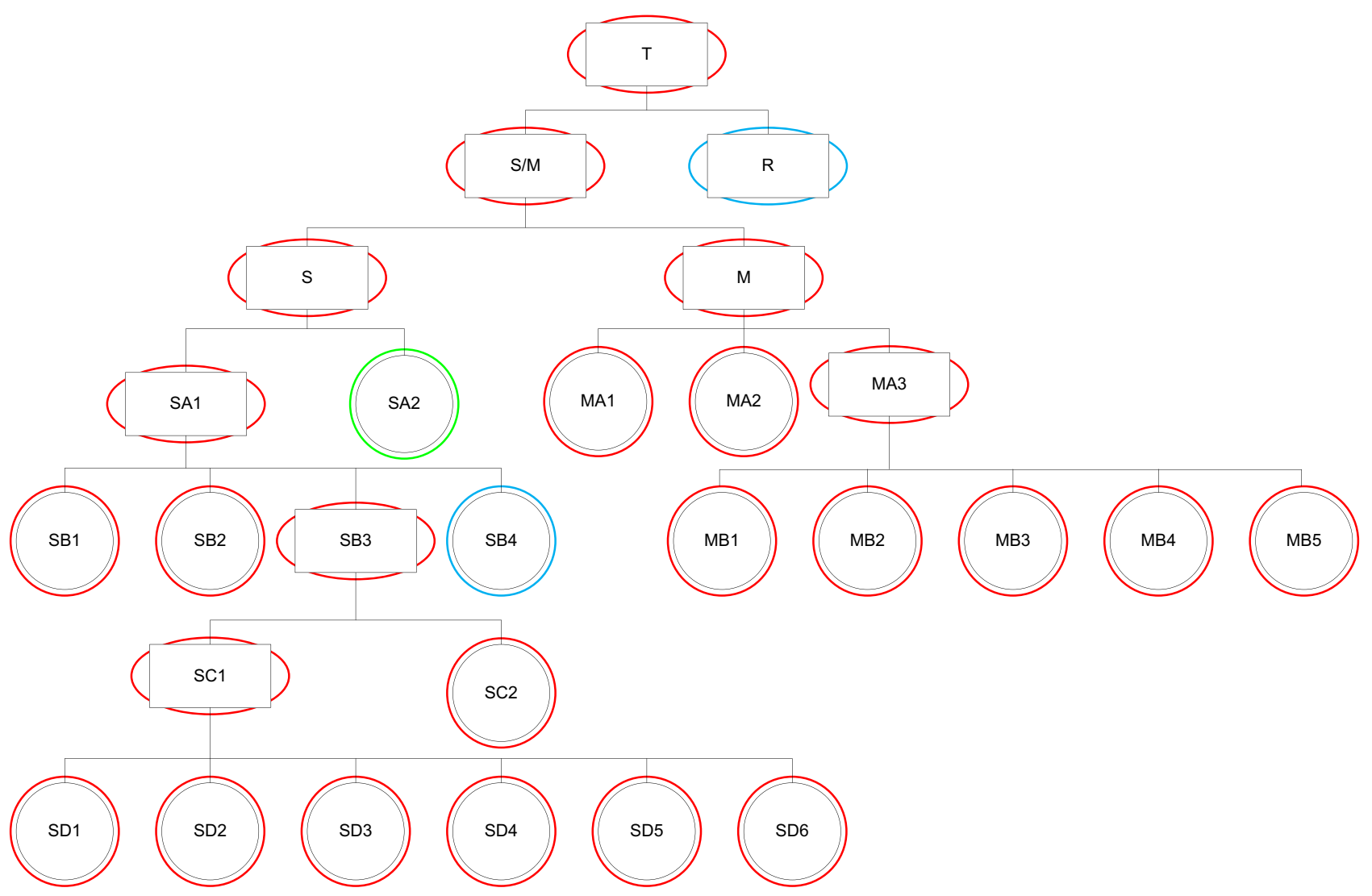

Fig. 6 Signaling of the main branches of the MORT method tree

Fig. 7 SB2 Branch

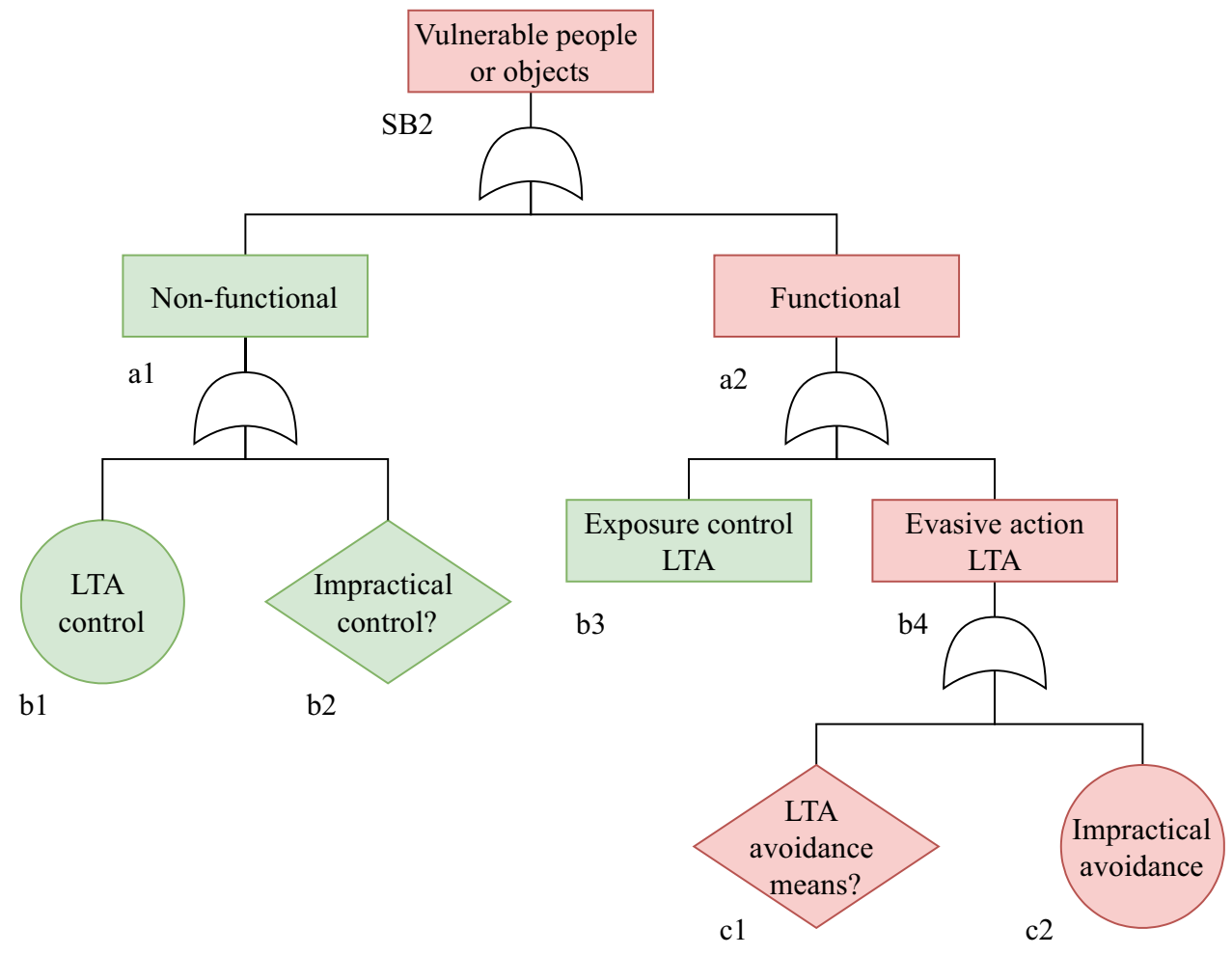


or satisfactory; and iii) blue, when the element needed more information to be able to judge it. Figure 6 illustrates the beginning of this stage.

All red elements were decomposed into branches of the MORT method tree, thus generating 16 branches: SB1, SB2, SD1, SD2, SD3, SD4, SD5, SD6, MA1, MA2, MB1, MB2, MB3, MB4 and MB5. Figures 7 and 8 illustrate how the branches were decomposed, using as reference, respectively, the branches SB2 and MB4.

Due to the high number of signaled elements, Table 7 was constructed to synthesize the results and facilitate understanding the main branches of the MORT method. Thus, it is important to remind that the decomposition of the branches followed a logic similar to that presented in Fig. 6 .

\section{Discussion of research results}

It is noticed, through the analysis, that the definition of risk that best represents the problem in question is that of Olson and $\mathrm{Wu}(2010)$, where they affirm that risk is the possibility of an event to affect negatively any person or organization. In fact, the incident in question is proof for this statement, since the damage to the valve is an unexpected event that has as a corrective measure the exchange of the damaged valve for a new one, which increases the costs of the process. In addition, if not resolved, its occurrence can interrupt the processes of other companies that are part of the supply chain and, most importantly, can expose workers to dangers that can be harmful to them. This demonstrates the vulnerability that Guo (2011) referred to, when defining the concept of supply chains.

Regarding the classification of this risk, this study considered the twelve possible types of risk suggested by Harland et al. (2003) and the risk classification system for a supply chain created by Rangel et al. (2014). However, the predominant classification was the operational risk, because, despite having financial factors as consequences, the incident happens during the cylinder requalification process.

According to Olson and $\mathrm{Wu}$ (2010), it is up to the company's management to minimize or, if possible, eliminate the probability of an unexpected event. If this is not possible, the consequences of this effect must be controlled to the extent that they do not deeply affect the company and its supply chain. As shown in Table 8, in all cases, the company did not take the appropriate measures, as it did not have any problem minimization policy. Moreover, it did not know how to control the consequences of the incident properly. The development of a new tool only began after some similar events had already occurred. This attitude of the company

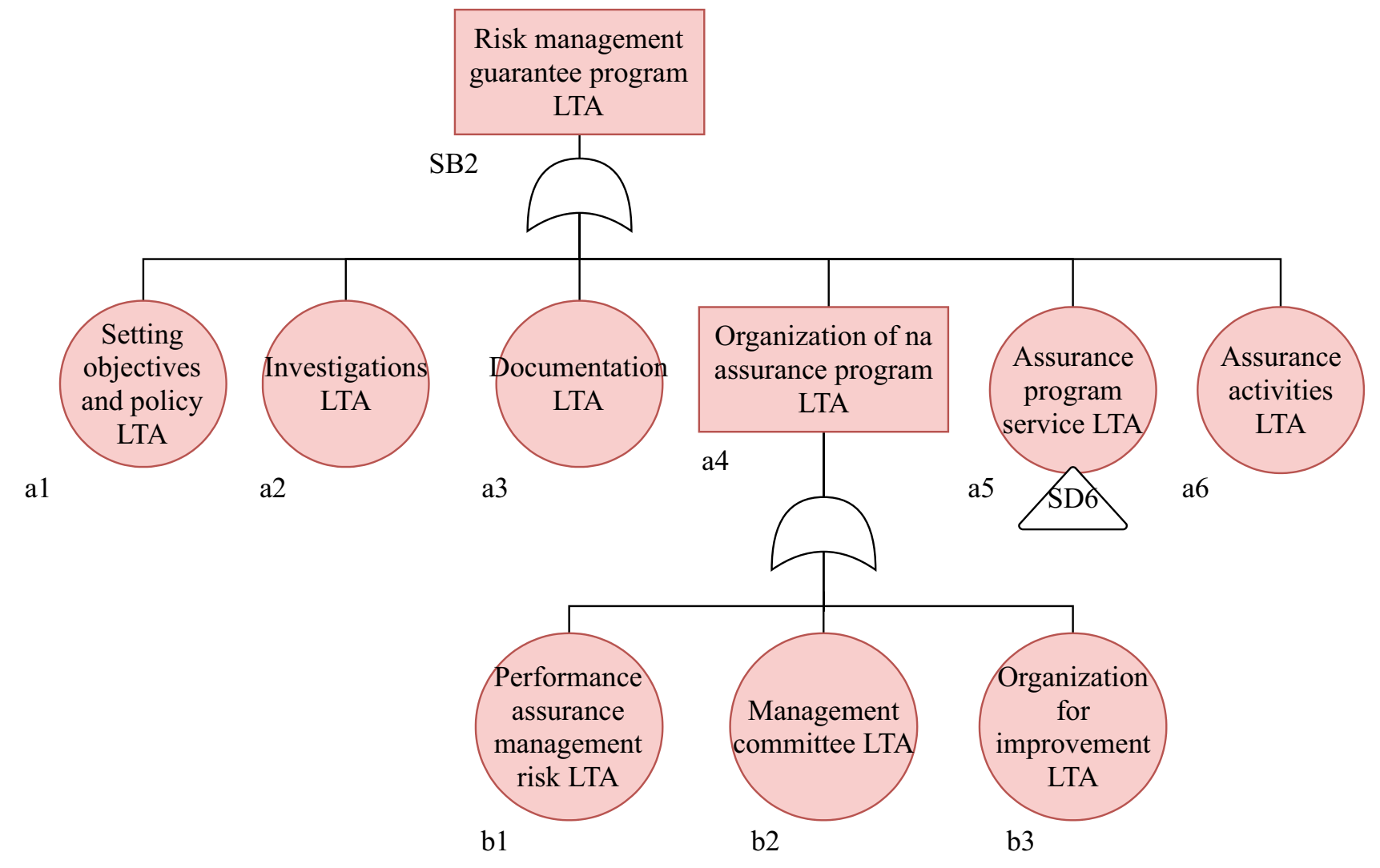

Fig. 8 MB4 Branch 
Table 7 Description of the results of the stages of the MORT method graph

\section{Branch Description}

$\mathrm{T} \quad$ The losses generated are due to the damage of the valve in the work process. When damaged, the valves need to be replaced with new ones and this represents a loss for the company; in addition, there is a loss of the company's credibility with the customer

S/M The aforementioned losses are the result of the company's "carelessness and omissions"

$\mathrm{R} \quad$ All the assumed risks indicated in the graph were assessed inappropriately. Later, in Table 8, it is explained better

S The "carelessness and omissions" are due to Control Factors LTA

SA1 The incident occurs when the energy flow (employee using the wrench) comes into contact with a target (valve) without a barrier or control protecting him/her

SB1 The harmful energy flow represented by the employee using the wrench is functional, that is, it is part of the process and the control of its use is deficient, as there is no adequate distance from the energy flow

SB2 The target (valve), as well as the energy flow, is also functional, as it is part of the process. Although the target is in place, the means to allow the flow of energy not to harm it have not been provided and used. For example: when realizing that the tool is poorly positioned on the valve, the employee can adjust the position, instead of continuing the process incorrectly

SB3 It considers whether the barriers and controls were adequate to prevent targets from being exposed to harmful energy flows

SC1 It considers whether the work and process control system in question was adequate

SD1 Regarding technical information, there have been past and recent investigations aimed at solving the problem in question, but they were not adequate

Regarding data collection, the company has not implemented a plan for monitoring the work process and does not have an adequate internal audit system to guarantee its quality. In addition, they did not adequately use information from previous similar incidents

Regarding data analysis, there is no problem priority checklist and status display point, where managers and supervisors can monitor current problems and perform analysis of results

The risk analysis carried out by the company aimed only to understand the consequences of the incident in question, that is, the problems in the work process were not sufficient to trigger a risk analysis before the incident. Another important point is that the training given by the company to employees was not the result of risk analysis, but an unplanned change of work

SD2 There was no specification of the operational readiness check, where resources such as facilities, equipment, control procedures and personnel were properly observed. The verification carried out was informal and did not guarantee the quality of the process

This branch of the tree shows us that an adequate check of operational readiness would show that the incident in question did not happen only due to an employee error, but also due to the use of inadequate equipment (wrench) in the valve removal and placement process

SD3 The inspection of processes and equipment did not follow a previously established plan, in which the exact time and place for some inspection were established

In addition, the coordination of activities is not adequate when certain equipment in the process undergoes maintenance, as there is no method in the company to minimize the effects of the absence of certain equipment and machines

SD4 Equipment maintenance did not follow an established plan. This service was outsourced when needed

In addition, the location where the incident occurs did not receive any maintenance service

SD5 The absence of a checklist of process risks, diagrams and records contributed to the incident in question, as it prevented the risks from being detected

The company did not realize the impact that the incident could have on costs and on the customer's perception, so it took time to look for solutions

Although the task was properly assigned to employees, it was not informed of its possible risks during the stages. This was due to an inadequate decision by the company to consider the activity with a low gravity potential

There was no risk prioritization procedure, where the potential severity of each one was measured. As there was no specific risk assessment for a task, no recommendation was made about the control of risks

SD6 The company's management did not develop norms and an internal regulation in the process where the incident occurred and could be controlled. Therefore, avoiding new occurrences

The use of available resources was harmful, as the tool used was inadequate, which generated rework and higher costs for the company

The company did not have a pre-established procedure for dealing with urgent or high-risk situations

SC2 Barriers for the energy flow were possible, but were not used. For example, the use of a suitable tool in the work process would prevent the employee's force from damaging the valve

The barriers between the energy flow (employee using the wrench) and the target (valve) were not considered before and, therefore, were not used

Barriers that would directly protect the target (valve) were also not considered and, therefore, were not used

SB4 Other events in the framework of barriers, in the future, need to be analyzed by the graph of the MORT method 
Table 7 (continued)

\section{Branch Description}

SA2 The company did not have an adequate response time to stabilize and restore the situation after the incident. The creation of a new tool to remove the valve was the solution found by the company to solve the problem, but it was not put into practice immediately, which subsequently generated similar incidents

M This branch considers how the planning or policy making processes may have contributed to the incident, that is, seeking to understand the aspects of the management system that allowed the elements of branch $\mathrm{S}$ to be inadequate

MA1 Despite meeting some basic corporate social responsibility requirements, such as labor rights, the company fails when thinking about policies. Specifically, because it does not have clearly defined values and this is not passed on to employees. In addition to not having policies related to tasks

MA2 Regarding the planning process, although the company took steps to minimize the effects of the incident in question, these were not related to policy planning. Another negative point is that the company did not have an efficient communication plan, where the flow of information could transmit the company's policies to all employees

There was no policy implementation plan, so most elements of MA2 are marked in red

MA3 This branch considers the adequacy of the risk management system

MB1 There was no risk management policy, therefore, this branch is marked with the color red

MB2 This branch considers whether the problem in question is the result of how the risk management policy was implemented. As there was no risk management policy, this branch is marked in red

MB3 The company has not established risk analysis criteria that could assist in controlling the flow of harmful energy. For example, there was no automatic machinery for removing and placing the valve; in the workplace there were no warnings to alert the employee to the flow of harmful energy; there was no safe procedure for controlling the flow of energy. In addition, the error made by the employee when disproportionately forcing the tool over the valve was not foreseen and this error is one of the main contributing factors for damaging the valves

The place where the process is carried out was also considered inappropriate, as the vise is on an uneven (uneven) floor. In addition, the equipment in use was not properly checked and tested. Supervision, although it exists, was not specified in relation to how to do this supervision, the amount needed, among other specifications

The company does not work with established goals, so it does not have indicators that can measure its performance

The use of harmful energy flow was not limited, being used excessively, without a barrier model or adequate control. In addition, there were no clear warnings for all situations where people or objects came into contact with harmful energy

There was no adequate guidance regarding the minimum number of supervisions to be carried out and about the responsibilities of supervisors in the work process

The company did not have a defined emergency method, in which instructions of procedure for the employees could be informed. Only equipment connected to a power system can be switched off using a general circuit breaker

There is no problem minimization policy and no adequate procedure to have a quick correction of these problems

MB4 All elements of this branch are marked in red, as there is no Risk Management Guarantee Program

MB5 It is noticed that there is no defined Risk Management System. The company analyzes the risks of a process informally, without quantifying and documenting them. Therefore, a review of the risk system is not carried out

Source: Own elaboration

reinforces what Khan and Burnes (2007) perceived within an organization, in which it is believed that the risk management process tends to be associated with the means to avoid losses, instead of seeking solely for advantages (especially economic).

Through the "M" branch of the MORT method analysis, it was noticed that the company did not have an established Risk Management System. Risks were analyzed informally, without being quantified, prioritized and monitored. Thus, the MORT method proved to be useful for carrying out the first stage of the risk management process, since it was able to identify, through the barrier framework, all the risks associated with the processes or activities in question.

According to Kingston et al. (2009), losses can be caused by risks that have not been properly managed-called "carelessness and omissions"-and by risks that have been correctly identified and accepted—called "assumed risks". During the process of answering the questions contained in the manual, some elements were marked with blue color and considered as an "assumed risk", as the company was aware of the possibility of an incident. Table 8 presents these elements. The "MORT reference" column locates the element in the MORT method graph, while the "description" column explains why the element is in that position. The last column, "Was the decision taken properly?", seeks to find out if the company has properly identified, assessed and quantified the risks that were taken.

The NRI-1 manual states that only those risks that have been properly analyzed should be considered "assumed risks", in other words, those that have been identified, evaluated, quantified and adequately controlled. As shown in 
Table 8 Assumed risks

\begin{tabular}{lll}
\hline MORT reference & Description & $\begin{array}{c}\text { Was the decision } \\
\text { taken properly? }\end{array}$ \\
\hline SB1-a2-b4-c2 & Did not use machinery to install and to remove de valve & No \\
SD5-a4-b3-c11-d9 & Consider the problem of damaging the valve with low risk potential & No \\
SC2-a1-b1 & $\begin{array}{l}\text { The barrier was not impossible and yet it was not implemented. Machinery to install } \\
\text { and remove the valve exists, addition, there were conditions to develop a suitable tool } \\
\text { for this process }\end{array}$ & No \\
The same barriers mentioned above were not provided by the manager & No company was slow to start looking for solutions to the problem in question. The \\
SA2-a1-b2-c6 & Neveloped tool was only implemented after a few incidents &
\end{tabular}

Source: Own elaboration

Table 8, all elements were considered to be inappropriate decisions; therefore, the elements must be marked with red in the graph.

\section{Conclusions}

It was observed in the literature that some techniques are commonly used to perform or support the SCRM, such as the Multicriteria Decision Support Methods. However, others were not even used, such as the MORT Method. Given this scenario, this brought interest in analyzing whether "tools" that are not usual for SCRM (at least in the literature) could be used in a real situation. Given that analyzing several "unusual" tools could be unfeasible (for reasons of time and resources) and that the MORT Method has some publications that illustrate its use (and none of them in supply chains), this research sought to answer the following question: is it possible to use the MORT Method in SCRM? From this problem question, this research was structured and developed, with a practical application of the MORT Method in a cylinder requalification company that is a relevant part of the supply chain of its main customers (DuPont, CocaCola, White Martins, among others). From this perspective, it is concluded that the present research achieved its main objective, generating practical implications and recommendations for future research, described and organized in the following sub-sections.

In addition to practical implications and recommendations for future research, this study presented at least three contributions to the literature on risk management i) applied, in an innovative way, the MORT Method in the management of supply chain risks; ii) found that the NRI Mort User's manual, developed by Kingston et al. (2009), is referenced by about $80 \%$ of published research on the MORT Method, thus presenting itself as an excellent starting point for those who wish to learn more about this method; iii) brought to light the discussion of an effective method of risk management that was underused in the literature, approaching the main publications on the subject and drawing the reader's attention to the use of this method.

\subsection{Practical and managerial implications}

With the help of process mapping, it was possible to start the first stage of the MORT Method, that is, to know the sequencing of the cylinder requalification activities (Fig. 4) and its unfolding in the activities of "valve removal" and "valving process" (Fig. 5) as those in which the incident "damage to cylinder valves" may occur. Continuing, Tables 3 and 4 developed energy tracking and barrier analysis, followed by energy transfer analysis (Tables 5 and 6), to finally identify, through the signaling of the main branches of the Method tree MORT (Fig. 6), the elements to be decomposed into the branches "control factors" (Fig. 7) and "management system factors" (Fig. 8).

When applying the MORT Method, it was possible to notice that the target company of this study did not have an established risk management system. Through the "M" branch of the MORT method analysis, it was possible for the company to analyze the risks of the "valve removal" and "valving process" in an informal way, without these being quantified, prioritized and monitored. This finding becomes clearer when looking at Table 7 , which concludes that even when the company was aware of the risks, they were not adequately assumed. Factors such as incorrect identification by the company of the causes of the incident, absence of an operational readiness check, use of an inadequate tool to remove the valve and delay in solving the problem represent the main failures for the incident in question.

As the main practical implication, this research brought an application of the MORT Method in a cylinder requalification company, which is an important part of the supply chain of several other organizations (Du Pont, Coca-Cola, White Martins, among others), unfolding such application in sequenced, detailed and exemplified steps, so that the MORT Method can be reproduced by other professionals who are 
interested in using it for the identification of "root causes" of incidents. In addition to professionals, researchers who are interested in developing studies on this method of risk management, including for the management of supply chain risks, may make use of the results of this research, since the case study carried out contributes with information on the subject, presenting the MORT method as a way to help identify contributing factors of an incident in a process.

Therefore, the research fulfills its main objective, by demonstrating the application of the MORT method in the SCRM of a company that provides services in the areas of manufacturing inspection, certification and requalification of cylinders for packaging and transporting gases to high and low pressure, as damaged cylinder valves have the potential to generate outages, explosions and fires in those who make use of their services.

\subsection{Limitations and recommendations for future research}

The present research has two limitations that, in our judgment, do not invalidate or impair the results presented here. The first limitation is related to the little research content found in journals about the MORT Method, which ended up affecting a literature review with little research directly related to this topic. Based on this limitation, we were careful to analyze the references used in the papers found, in order to expand the theoretical framework to be used. It was precisely in this action that the NRI-1 manual (Kingston et al. 2009) was found to be used (referenced) by most authors who published some work involving the MORT Method; and which ended up being the main material for conducting the empirical study in the cylinder company. In this sense, this research helps to minimize this gap, as it presents a case study with practical application of the MORT Method, constituting yet another material to be used by researchers in future studies.

From this first limitation, it is suggested the development of a theoretical and conceptual research (such as a systematic literature review) from materials with technical and professional characteristics, such as standards, technical reports, technical magazines, manuals, among other materials that can increase knowledge about the use of the MORT Method.

The second limitation of this work is related to the use of a single case study for the application of the MORT Method, which prevents the findings observed here from being generalized to other companies; even those from the same sector or field of activity. Despite this limitation, it is believed that the sequenced and logical way in which the research was conducted, mainly in the organization and presentation of its results, allows similar procedures to be adopted, systematized and conducted by other researchers and/or professionals who want to use the MORT Method. Under our perspective, the most relevant thing here is not to generalize the results, but rather to explore the use of a risk management method that is little used by professionals and researchers. As positive aspects of the case study, and which, in a way, brings more robustness to the results of this research, is the twenty-year professional experience of the interviewees who participated in this study.

Based on this second limitation, it is recommended that future research be carried out to identify professionals who have experience in applying the MORT Method, so that their reports and experiences on this risk management method can be captured, condensed and organized into a single research or technical report, thus bringing more professional knowledge about the MORT Method.

Finally, it is observed in the literature the application of several traditional techniques, together or separately, for SCRM, such as the FMEA, Delphi Method, MultiCriteria Decision Analysis and Monte Carlo Simulation. However, one of the greatest challenges for future research is to assess the applicability of other tools that have never been used in the SCRM. Thus, techniques that have rarely been used should also be considered to improve the results obtained from their applications.

Author contribution Ualison Rébula de Oliveira: Conceptualization, Methodology, Writing — Review \& Editing, Visualization, Supervision, Project administration. Camila Oliveira dos Santos: Conceptualization, Investigation, Resources, Formal analysis, Writing-Original Draft. Gabriel Elias Lunz Chaves: Conceptualization, Investigation, Resources, Formal analysis, Writing-Original Draft. Vicente Aprigliano Fernandes: Writing —-Review \& Editing.

Funding No funding was received to assist with the preparation of this manuscript.

Availability of data and material Not applicable for this research.

Code availability Not applicable for this research.

\section{Declarations}

Ethics approval Not applicable for this research

Conflicts of interest The authors have no conflicts of interest to declare that are relevant to the content of this article.

\section{References}

Abdel-Basset M, Mohamed R (2020) A novel plithogenic TOPSISCRITIC model for sustainable supply chain risk management. J Clean Prod 247:119586. https://doi.org/10.1016/j.jclepro.2019. 119586 
Ahmed S, Kalsoom T, Ramzan N, Pervez Z, Azmat M, Zeb B, Ur Rehman M (2021) Towards Supply Chain Visibility Using Internet of Things: A Dyadic Analysis Review. Sensors 21(12):4158. https://doi.org/10.3390/s21124158

Ahmed W, Huma S (2021) Impact of lean and agile strategies on supply chain risk management. Total Qual Manag Bus Excell 32(1-2):33-56. https://doi.org/10.1080/14783363.2018.1529558

Azmat M, Atif M, Kummer S (2019) Identification and prioritization of critical success factors in faith-based and non-faith-based organizations' humanitarian supply chain. J Int Humanit Action 4(1):1-17. https://doi.org/10.1186/s41018-019-0067-6

Baryannis G, Validi S, Dani S, Antoniou G (2019) Supply chain risk management and artificial intelligence: state of the art and future research directions. Int J Prod Res 57(7):2179-2202. https://doi.org/10.1080/00207543.2018.1530476

Blome C, Schoenherr T (2011) Supply chain risk management in financial crises: a multiple case-study approach. Int J Prod Econ 134(1):43-57. https://doi.org/10.1016/j.ijpe.2011.01.002

Blos MF, Quaddus M, Wee HM, Watanabe K (2009) Supply chain risk management (SCRM): a case study on the automotive and electronic industries in Brazil. Supply Chain Manag 14(4):247252. https://doi.org/10.1108/13598540910970072

Bouncken RB (2011) Supply Chain Contingencies: The Effects of Up-Stream Directives on Supplier's Innovation Performance. Eng Manag J 23(4):36-46. https://doi.org/10.1080/10429247. 2011.11431918

Chen PS, Wu MT (2013) A modified failure mode and effects analysis method for supplier selection problems in the supply chain risk environment: A case study. Comput Ind Eng 66(4):634642. https://doi.org/10.1016/j.cie.2013.09.018

Creazza A, Colicchia C, Spiezia S, Dallari F (2021) Who cares? Supply Chain Managers' Perceptions regarding Cyber Supply Chain Risk Management in the Digital Transformation Era Supply Chain Manag in-Press. https://doi.org/10.1108/SCM-02-2020-0073

Cunha L, Ceryno P, Leiras A (2019) Social supply chain risk management: A taxonomy, a framework and a research agenda. J Clean Prod 220:1101-1110. https://doi.org/10.1016/j.jclepro. 2019.02.183

Daghfous A, Qazi A, Khan MS (2021) Incorporating the risk of knowledge loss in supply chain risk management. Int J Logist Manag 32(4):1384-1405. https://doi.org/10.1108/IJLM-06-2020-0225

De Oliveira UR, Aparecida Neto L, Abreu PAF, Fernandes VA (2021) Risk management applied to the reverse logistics of solid waste. J Clean Prod 296:126517. https://doi.org/10.1016/j.jclepro.2021. 126517

De Oliveira UR, Espindola LS, Marins FAS (2018) Analysis of supply chain risk management researches. Manag Oper Rev 25(4):671-695. https://doi.org/10.1590/0104-530x3515-16

De Oliveira UR, Marins FAZ, Rocha HM, Salomon VAP (2017) The ISO 31000 standard in supply chain risk managemnet. J Clean Prod 151:616-633. https://doi.org/10.1016/j.jclepro.2017.03.054

De Oliveira UR, Paiva EJD, Almeida DAD (2010) Fault mapping integrated methodology: an approach to using process mapping with FTA and FMEA techniques and supported by expert's critical analysis. Production 20(1):77-91. https://doi.org/10.1590/ S0103-65132010005000004

de Souza Feitosa ISC, Carpinetti LCR, de Almeida-Filho AT (2021) A supply chain risk management maturity model and a multicriteria classification approach. Bench Int J 28(9):2636-2655. https://doi.org/10.1108/BIJ-09-2020-0487

Dias GC, Leal Junior IC, De Oliveira UR (2019) Supply chain risk management at seaport container terminals. Manag Oper Rev 26(3):1-14. https://doi.org/10.1590/0104-530X4900-19

Dias GC, Hernandez CT, De Oliveira UR (2020) Supply chain risk management and risk ranking in the automotive industry. Manag Oper Rev 27(1):1-21. https://doi.org/10.1590/0104-530x3800-20
Dias GC, de Oliveira UR, Lima GBA, Fernandes VA (2021) Risk Management in the Import/Export Process of an Automobile Company: A Contribution for Supply Chain Sustainability. Sustainability 13:6049. https://doi.org/10.3390/su13116049

El Baz J, Ruel S (2021) Can supply chain risk management practices mitigate the disruption impacts on supply chains' resilience and robustness? Evidence from an empirical survey in a COVID-19 outbreak era. Int J Prod Econ 233:107972. https://doi.org/10. 1016/j.ijpe.2020.107972

Ferjencik M, Kuracina R (2008) MORT WorkSheet or how to make MORT analysis easy. J Hazard Mater 151:143-154. https://doi. org/10.1016/j.jhazmat.2007.05.064

Ghadge A, Dani S, Kalawsky R (2012) Supply chain risk management: present and future scope. Int J Logist Manag 23(3):313-339. https://doi.org/10.1108/09574091211289200

Gerbec M (2013) Supporting organizational learning by comparing activities and outcomes of the safety-management system. J Loss Prev Process Ind 26:1113-1127. https://doi.org/10.1016/j.jlp. 2013.04.009

Gopalaswami N, Han Z (2020) Analysis of laboratory incident database. J Loss Prev Process Ind 64:1-10. https://doi.org/10.1016/j. jlp.2019.104027

Guo Y (2011) Research on knowledge-Oriented Supply Chain Risk Management System Model. J Strategy Manag 2(2):72-77. https://doi.org/10.5430/jms.v2n2p72

Harland C, Brenchley R, Walker H (2003) Risk in supply network. J Purch Supply Manag 9(2):51-62. https://doi.org/10.1016/S14784092(03)00004-9

Hosseini S, Ivanov D, Dolgui A (2020) Ripple effect modelling of supplier disruption: integrated Markov chain and dynamic Bayesian network approach. Int J Prod Res 58(11):3284-3303. https://doi. org/10.1080/00207543.2019.1661538

ISO (2009) Risk Management-Risk Assessment Techniques: ISO 31010; ISO: Geneve, Switzerland

Jooma Z, Hutchings J, Hoagland H (2015) The Development of Questions to Determine the Effectiveness of the Incident Investigation Process for Electrical Incidents. IEEE Trans Ind Appl 51(5):42454254. https://doi.org/10.1109/TIA.2015.2431645

Jooma Z, Hutchings J, Hoagland E, Jandrell IR (2016) The Analysis of an Incident Investigation System. IEEE Trans Ind Appl 52(6):5235-5240. https://doi.org/10.1109/ESW.2016.7499713

Juttner U, Peck H, Christopher M (2003) Supply Chain Risk Management: Outlining an agenda for future research. Int J Logist Res Appl 6(4):97-210. https://doi.org/10.1080/13675560310001627016

Khan O, Burnes B (2007) Risk and Supply Chain Management: Creating a Research Agenda. Int J Logist Manag 18(2):197-216. https://doi.org/10.1108/09574090710816931

Kwak D, Rodrigues VS, Mason R, Pettit S, Beresford A (2018) Risk interaction identification in international supply chain logistics: Developing a holistic model. Int J Oper Prod Manag 38(2):372389. https://doi.org/10.1108/IJOPM-03-2016-0121

Kern D, Moser R, Hartmann E, Moder M (2012) Supply risk management: model development and empirical analysis. Int J Phys Distrib Logist Manag 42(1):60-82. https://doi.org/10.1108/09600031211202472

Kim DH, Cho WI, Lee SJ (2020) Fault tree analysis as a quantitative hazard analysis with a novel method for estimating the fault probability of microbial contamination: A model food case study. Food Control 110:1-6. https://doi.org/10.1016/j.foodcont.2019.107019

Kingston J, Koornneef F, Ruilt JV, Frei R, Schallier P (2009) NRI MORT User's Manual: for use with the management oversight and risk tree analytical logic diagram. Second edition. The Noordwijk Risk Initiative Foundation. ISBN: 978-90-77284-08-7. https:// www.nri.eu.com/NRI1.pdf

Machado LDV, De Oliveira UR (2021) Analysis of failures in the accessibility of university buildings. J Build Eng 33:101654. https://doi.org/10.1016/j.jobe.2020.101654 
Manuj I, Mentzer JT (2008) Global Supply Chain Risk Management. J Bus Logist 29(1):133-155. https://doi.org/10.1002/j.2158-1592. 2008.tb00072.x

Mohammadfam I, Mohseni S, Sohrabi MS, Arani MH, Rezapour HA (2016) Helping HSE team in learning from accident by using the Management Oversight and Risk Tree (MORT) analysis Method. J Environ Health Sustain Dev 1(2):102-110. http://jehsd.ssu.ac. ir/article-1-69-en.html

Mohib AMN, Deif AM (2020) Supply chain multi-state risk assessment using universal generating function. Prod Plan Control 31(9):699_ 708. https://doi.org/10.1080/09537287.2019.1680891

Munir M, Jajja MSS, Chatha KA, Farooq S (2020) Supply chain risk management and operational performance: The enabling role of supply chain integration. Int J Prod Econ 227:107667. https://doi. org/10.1016/j.ijpe.2020.107667

Norrman A, Wieland A (2020) The development of supply chain risk management over time: revisiting Ericsson. Int J Phys Distrib Logist Manag 50(6):641-666. https://doi.org/10.1108/ IJPDLM-07-2019-0219

Ojha R, Ghadge A, Tiwari MK, Bititci US (2018) Bayesian network modelling for supply chain risk propagation. Int J Prod Res 56(17):57955819. https://doi.org/10.1080/00207543.2018.1467059

Oehmen J, Ziegenbein A, Alard R, Schönsleben P (2009) Systemoriented supply chain risk management. Prod Plan Control 20(4):343-361. https://doi.org/10.1080/09537280902843789

Olson DL, Wu DD (2010) A Review of Enterprise Risk Management in Supply Chain. Kybernetes 39(5):694-706. https://doi.org/10. 1108/03684921011043198

Rangel DA, Oliveira TK, Leite MSA (2014) Supply Chain Risk Classification: discussion and proposal. Int J Prod Res 52(12):1-20. https://doi.org/10.1080/00207543.2014.910620

Rezaee MJ, Yousefi S, Eshkevari M, Valipour M, Saberi M (2020) Risk analysis of health, safety and environment in chemical industry integrating linguistic FMEA, fuzzy inference system and fuzzy DEA. Stoch Environ Res Risk Assess 34:201-218. https://doi. org/10.1007/s00477-019-01754-3

Ritchie B, Brindley C (2007) Supply chain risk management and performance: A guiding framework for future development. Int J Oper Prod Res 27(3):303-322. https://doi.org/10.1108/01443570710725563

Ruiz-Torres AJ, Mahmoodi F, Zeng AZ (2013) Supplier selection model with contingency planning for supplier failures. Comput Ind Eng 66(2):374-382. https://doi.org/10.1016/j.cie.2013.06.021

Saglam YC, Çankaya SY, Sezen B (2020) Proactive risk mitigation strategies and supply chain risk management performance: an empirical analysis for manufacturing firms in Turkey. J Manuf Technol Manag 32(6):1224-1244. https://doi.org/10.1108/ JMTM-08-2019-0299

Samson D, Gloet M (2018) Integrating performance and risk aspects of supply chain design processes. Prod Plan Control 29(15):12381257. https://doi.org/10.1080/09537287.2018.1520314
Santos RB, Oliveira UR, Rocha HM (2018) Failure mapping for occupational safety management in the film and television industry. Int J Prod Econ 203:01-12. https://doi.org/10.1016/j.ijpe.2018.05.024

Santos RB, De Oliveira UR (2019) Analysis of occupational risk management tools for the film and television industry. Int J Ind Ergon 72:199-211. https://doi.org/10.1016/j.ergon.2019.05.002

Santos-Reyes J, Olmos-Penã S, Alvarado-Corona R, Hernández-Simón L (2009) Applying MORT to the analysis of the "Tláhuac"' incident. Reliab Eng Syst Saf 94:1547-1556. https://doi.org/10.1016/j. ress.2009.02.019

Santos-Reyes J, Alvarado-Corona R, Olmos-Peña S (2010) Learning from Tabasco's floods by applying MORT. Saf Sci 48:1351-1360. https://doi.org/10.1016/j.ssci.2010.05.008

Santos-Reyes J, Olmos-Penã S (2017) Analysis of the 'News Divine' stampede disaster. Saf Sci 91:11-23. https://doi.org/10.1016/j. ssci.2016.07.014

Silva LMF, de Oliveira ACR, Leite MSA, Marins FAS (2021) Risk assessment model using conditional probability and simulation: case study in a piped gas supply chain in Brazil. Int J Prod Res 59(10):2960-2976. https://doi.org/10.1080/00207543.2020.1744764

Tang CS (2006) Perspectives in supply chain risk management. Int J Prod Econ 103(2):51-488. https://doi.org/10.1016/j.ijpe.2005. 12.006

Tang O, Musa SN (2011) Identifying risk issues and research advancements in supply chain risk management. Int J Prod Econ 133(1):25-34. https://doi.org/10.1016/j.ijpe.2010.06.013

Thun JH, Hoenig D (2011) An empirical analysis of supply chain risk management in the German automotive industry. Int J Prod Econ 131(1):242-249. https://doi.org/10.1016/j.ijpe.2009.10.010

Tummala R, Schoenherr T (2011) Assessing and managing risks using the Supply Chain Risk Management Process (SCRMP). Supply Chain Manag Int J 16(6):474-483. https://doi.org/10. 1108/13598541111171165

Vaughan EJ (1997) Risk Management. John Willey \& Sons, New York

Viswanadham N, Gaonkar RS (2008) Risk Management in Global Supply Chain Networks. In: Tang CS., Teo CP, Wei KK. (eds) Supply Chain Analysis. Int Series Oper Res Manag. Springer, Boston, 119. https://doi.org/10.1007/978-0-387-75240-2_8

Wang-Mlynek L, Foerstl K (2020) Barriers to multi-tier supply chain risk management. Int J Logist Manag 31(3):465-487. https://doi. org/10.1108/IJLM-09-2019-0256

Wang X, Tiwari P, Chen X (2017) Communicating supply chain risks and mitigation strategies: a comprehensive framework. Prod Plan Control 28(13):1023-1036. https://doi.org/10.1080/09537287. 2017.1329562

Yin RK (2017) Case Study Research and Applications: Design and Methods, 6a. Sage, New York

Publisher's Note Springer Nature remains neutral with regard to jurisdictional claims in published maps and institutional affiliations. 